\title{
J. Schivell
}

EEPTEMBER 1986

\section{PLASMA PHYSICS LABORATORY}

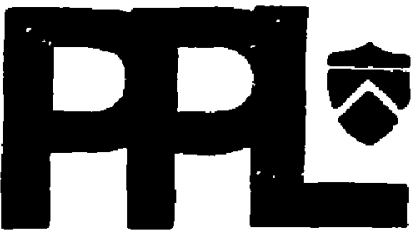

\section{PRINCETON UNIVERSITY} PRINCETON, NEW JERSEY

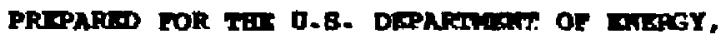
ONDSI CONIRACT DE-ACO2-75-CLO-3073. 


\section{RECONSTRUCTION OF PLASMA RADIATION FEATURES FROM PROJECTIONS}

MEASURED HITH TWO BOLOMETER ARRAYS

PPPL- -2382

J. Schivel1

DEB 7000670

Plasma Physics Laboratory, Princeton University

Princeton, New Jersey 08544

\section{ABSTRACT}

A specialized method has been developed to maximize the two-dimensional detail obtained from two perpendicular bolometer arrays. The technique relies on the assumption that poioidal variation exists only near the plasma surface. The cross section is divided into appropriate zones, and the emittance is reconstructed by a numerical method. The position, intensity, and width of large features are clearly displayed. A marfe is tracked as it drifts around the plasma and evolves into a radiating shell detached from the Iimiter. A central peak, plus inner-wall radiating layer, plus a marfe appear in a highdensitj case reached by pellet injection.

\section{DISCLAIMER}

This report was prepared as an account of work spensored by an agency of the United States Government. Neither the United States Government nor any agency theres?, noz any of their tmployecs, makes any warranty, exptess or implied, or assumes any legal liabulity or responsibility for the accuracy, completencss, or usefulness of any information. apparatus, product, or process disclesed. or represents that its use mould not infringe privately owred rights. Refer. ence herein to any specific commercial producl. p-oeess, or service by trade nami, trudemark, manufaeturer, or olherwise does not necessarily conseitute or imply its endorstment, recomatendation, or favoring by the United Siates Goverament or any agency thereor. The views and opinions of authors expressed hercin do not necessarily state or reflect those of the Uniled States Government of any agency thereof. 
INTRODJICTION

In the TFTR tokamak the power losses through impurity radiation are measured with several bolometers, among which are two fan arrays of 19 chords each [1]. The coverage of these arrays is diagramed in Fig. 1 . The field of view of each detector is approximately $0.1 \mathrm{~m}$. It was expected, and usually found, that the profiles of chord-integral power measured with the two arrays are at least approximately symmetric about the plasma center. However, when the plasma density is high for the operating conditions, an intense, narrow peak appears and seems to be superimposed on the normal profiles (Fig. 2). Erom its behavior in the radiation profiles and its behavior in the observations of other diagnosties, this phenomenon has been identified as the edge-plasma effect first seen on Alcator $C$ and named "marfe" [2]. A marfe is an intensely radiating, cold, dense, region of plasma on the inner side of the discharge. It is toroidally symmetric; that is, it has no helicity. Marfe observations on TFTR have been described in Ref. 3. New features observed (Fig. 3) are that the band drifts up or down the inner side of the plasma and that, if the density is pushed tigher, the band evolves into a bright shell surrounding the whole plasma and radiating all of the energy throughput.

The bolometer array measurements are central to these observations. In the radiated-power profiles the marfe is typically a large feature, with an intensity which is as great, or greater, than the intensity of the normal part. of the plasma. The coverage provided by the two arrays allows the marfe drift to be tracked continuously (while it drifts in and out of the field of view of other diagnostics), and the ahsolutely calibrated measurements can tell the power radiated by the marfe and its role in the plasma power balance. By locating the peaks on a diagram such as Fig. 1, one can see that the marfe has little or no rotational transform, In fact, one can also make a rough 
estimate of the power radiated per unit volume and the width of the band. However, it is cleariy worthwhile to make a proper reconstruction of the emittance as a function of radius and angle. With a well-specified procedure the reconstruction can be done routinely by computer. illso, one can check the consistency of the peaks from the two arrays and put an upper limit on possible helicity of the bright band. Finally, there are other features of radiation profiles which call for two-dimensional reconstruction: One, when the plasma is run in contact with the so-called inner bumper limiter, there is apparently a bright sheet of radiation on the whole inner side of the plasma. Two, when the density is very high as a result of pellet injection, there is evidence of a sharp central peak which needs to be distinguished from that bright background.

\section{RECONSTRUCTION METHOD}

The profiles from the two bolometer arrays constitute two projections of the cross section of the radiated power. Two projections give only limited information. For example, if the emittance in two dinensions is represented by harmonies in angle $[4,5]$,

$$
\begin{aligned}
E(r, \theta)=E_{0}(r) & +\sum_{m} E c, m(r) \cos (m \theta) \\
& +\sum_{m} E s, m(r) \sin (m \theta)
\end{aligned}
$$

two projections are sufficient to determine only terms through $\cos 2 \theta$. If, on the other hand, sne adopts a representation, say, of a grid with a large number of divisions and a constant emittance in each box, and applies the 
method of Maximum Entropy [6] to select a solution from the underconstrained possibilities, then the result is to spread out the emittance over the widest possible area consistent with the measurements.

What was done in this work, instead, was to assume that the interesting features are all in the auter layers of the plasma, and, further, on the inner side of these outer layers. These assumptions are not rigorously justified, but are indicated by all of the other observations [2, 3]. Actually, when the radiation peak is centered on channel 3 of the vertical view, there is little doubt about where the bright band must be or its thickness. When it is in the lower part of the plasma, it is natural to guess that it is no thicker. Observations by other diagnostics, such as the visible-light, tangentially viewing plasina $T V[7]$, and the multichannel infrared interferometer [8], support this assumption. Finally, it seems plausible that poloidally local effects are much more likely to occur in the outer portion of the plasma, which is closer to the influence of edge perturbations.

The assumptions allow one to utilize the available resolution in the interesting region. The cross section of the plasma is divided into zones as shown in Fig. 4. The emittance in each zone is a single value. The inner zones are annuli, while the outer ones are annuli subdlulded into sectors on the inner side. Zone boundaries were chosen so that at least one chord from each view passes through each zone. Due to the difficulties of our particular geometric arrangement, it was not possible to have zones nicely centered around each chord in many places. The effect is extra noisiness in the result; since the emittance in some zones is not well determined. To allow for the possibilfty of emittance in areas of the vacuum vessel outside of the nominal plasma toundary, additional rings were added, sectored as shown in the figure. 
The length of each chord, $i$, in each zone, $j$, was calculated to make up a matrix, $L_{i j}$. (To take into account the finite field of view of each detector, $L_{i f}$ was actually calculated by averaging over a number of chords distributed over a small range around each chord, $i$.) If the integral of the emittance along chord $i$ is $C_{i}$, and the emittance in zone $j$ is $E_{j}$, then the $C^{\prime} s$ and $E^{\prime} s$ are reiated by

$$
c_{i}=\sum_{j} L_{i j} E_{j}
$$

and, of course, the reconstruction consists of finding the $\left[E_{j}\right\}$. A linear, additive algebraic reconstruction technique (ART) [9] was used. The procedure is the same as that described in Ref. 10. The chords are stepped through, one by one, and th $E_{j}$ along each chord are adjusted to reduce the difference between the $C_{i}$ from Eq. (2) and the measured $C_{i}$. The adjustment to each $E_{j}$ is proportional to the length interval of the chord in the $j$-th zone. There is a convergence factor to specify what fraction of the difference is to be eliminated in each pass, and a large number of passes is used. Negative $E_{j}$ values are set to zero, and the other $E_{j}$ along the same chord are reduced to keep the sum unchanged. (There are two differences from Ref. 10. An error was corrected, so that in effecting the constraint that no $E_{j}$ be $<0$, the nonnegative $E_{j}$ are replaced by $E_{j}+N L_{i j} / \delta_{i m} L_{i m}{ }^{2}$, where $m$ ranges over all $\mathrm{j}$ such that $E_{j}>0$. The other difference is that there is a tolerance and a cutoff in the adjustment procedure for $E_{j}<0$. )

This procedure is resilient. It does not demand that there be an equal number of chords and emittance zones. The numbers used here are 38 chords and 41 zones. When the solution is underconstrained, the emittance is distributed over all possible zones, consistent with the observed $\left(\mathrm{c}_{1}\right)$. On the other 
hand, when the input data contains inconsistencies, such as a different average intensity in the two projections, the procedure averages among them, as long as the convergence factor is small. This averaging property is particularly useful on TFTR, since the bolometer arrays are on opposite sides of the torus. Finally, however, one must keep in mind that it is possible to converge on a fit that is good, but that does not correspond to reality.

RESULTS

The results of reconstructing a typical set of profiles are given in Figs. 2 and 5. Deviations from the observed profiles are mostly less than a few percent. The height of the marfe is $200 \mathrm{~kW} / \mathrm{m}^{3}$, and it is at least two zones (approximately $0.15 \mathrm{~m}$ ) thick. (If the zones were to be sectored in the smaller-radius ings, the reconstruction could yield a thicker marfe at some times, with correspondingly smaller height. However, the narrowness of the peak when the marfe is in the upper half, e. g., at $2.5 \mathrm{~s}$ (Fig. 2), indicates a small thickness.) The upward motion of the marfe along the inner side of the plasma is clearly seen. Beginning at $3.5 \mathrm{~s}$ the dominant pattern of radiation loss changes to a bright shell surrounding the plasma, steadily shrinking in diameter, At these times the symmetry in the ahord-integral profiles is clear. The reconstruction, since it uses inner rings which are not divided into sectors, does not prove the symnetry of the emittance, but makes use of it. The origin of the small peaks cutside the bright ring is not clear. They may be an example of an unreal $f i t$, as mentioned above.

As a test, this reconstruction procedure has been generalized to the case in which all of the rings are subdivided into sectors. As expected, the resulting emittance distributions showed streaks across the plasma diong the chords with high signals. Since the two projections available cannot 
dlstinguish between this kind of result and the edge concentration assumed above, it is up to the user to choose whlch result is proferable in light of other Information.

The emittance results are also produced as contour plots and plots in which the density of dots is proportlonat to emittanco, the surface plots are the most useful for maximum vigibility of the rentures.

Pigure 6 shews resilts at a time $600 \mathrm{~ms}$ arter the last in a series of 5 frozen deuterium pelletg has bcen injected into a discharge; the density reached a record high level. The reconstmution algorithm lits, in addition to a marfe in the inuer side, a sharp central penk. Evidence for this peak is seen directly in Fig. 6 (b) at vertical-view channel 9 . In the horizontal view it is apparentiy submerged in the marfe peak. It is interesting to note that this peak is predicted by caleulations of deuterium bremsstrahlung and impurity radiation for the density profile in this plasma [111.

The total power radiated from each zone can be found by multiplying the emittance by the toroldal volume of the zone, and the tutal for the whole plasma by summing over zones. in the drifting marfe case above, the marfe radiated power (taking a rough cut for the extent of the marfe) is $300 \mathrm{~kW}$, the remainder of the power from the imner-side surface of the plasma is $200 \mathrm{~kW}$, and the total from the rest, or "normal" part of the plasma, is $500 \mathrm{~kW}$. It is worth noting that, if the marfe is truly concentrated as shown, then the emittance is flve times the typical valur radiated froin the most intense region (near the surface) of the normat part of the plasmit. The poloidal extent of the marfe (width at hall maximum) is approximately $60^{\circ}$, but extend: about $90^{\circ}$ as it passes through the midplane. In the pellet case the peak mare emittance is $600 \mathrm{~kW} / \mathrm{m}^{3}$, and the certral peak is $300 \mathrm{~kW} / \mathrm{m}^{3}$. The $1 \mathrm{ntegrated}$ radlation losses are as follows: from the vielnlty of the inner wall, 
including the marfe, $1400 \mathrm{~kW}$; from the central peak, $350 \mathrm{~kW}$; and, from the rest of the plasma, $150 \mathrm{~kW}$. In thls case $100 \%$ of the input heating power is lost through radiation, but $75 \%$ of that is from the region near the inner wall. It is the case, however, that at the plasma center the local radiation loss is approximately equal to the local heating power.

Since the peaks in the two profiles are both fit, I find toroidal symmetry in the intensity, width, and poloidal location of the bright band. The amount of poloidal rotation of the band is less than $5^{\circ}$ in going one-half the way around the torus. of course, the peaks would also be consistent with a large poloidal rotation, e.g., $70^{\circ}$ in this case between arrays. However, that amount of rotation is inconsistent with the rotational transform of the magnetic field 1 ines, $32^{\circ}$, and with the picture from the plasma TV [7].

Sensitivity to noise was tested by adding normally distributed random errors to measured profiles and carrying out the reconstruction. A standard deviation of $10 \mathrm{~kW} / \mathrm{m}^{2}$ resulted in a standard deviation of $50 \mathrm{~kW} / \mathrm{m}^{3}$ in the emittance. This corresponds roughly to a doubling of the fractional error. An estimate of the sensitivity to the locations of the zone boundaries was made by comparing a case in which the Lij were calculated for zero-width fields of view with the case of normal fields $\left(4^{\circ}\right)$. For almost all zones there was little difference in the result, but one zone on the upper, inner side developed an apparently spurious peak $\left(200 \mathrm{~kW} / \mathrm{m}^{3}\right.$ in the $4.00 \mathrm{~s}$ reconstruction of Fig. 5), which is small in the normal-field case. These tests, as well as expe, ience with numerous reconstructiors, indicate that the stability of the method is good. 


\section{CONCLUSIONS}

The accuracy of the resuits is limited by the same sort of sensitivity to errors as the usual abel inversion for cylindrically symmetric situations [12]. In the TFTR case, the accuracy is also limited by the fact that the two arrays are on opposite sides of the torus. The assumption of relatively large, discrete zones with uniform emittance in each leads to rough spatial variations in the results.

Often there are features which do not fit, such as bumps, edge cusps, and skewness in the two profiles, with amplitudes of about $20 \%$ or less of the main part of the profile. The ART tends to average between the two views. In many rases the reasons for these features are not known. One known cause is a plume of impurities which comes off the 1 imiter rail [7] and apparently passes in front of the vertically viewing array, $36^{\circ}$ around the torus. For this reason, with rail-limited plasmas the outer half of the vertically viewed profile is often excluded from the fit.

In any case, this method is successful. It finds a fit to the height and width of large peaks in the two views. It indicates that the model, with its sectored zones on the inner side, is consistent with the measured profiles. The smaller bumps which result are generaliy not very reliable. They can suggest the existence of phenomena, to be confirmed by other evidence.

\section{ACKNOWLEDGMENTS}

I wish tc thank $C$. E. Bush, M. Zarnstorff, and B. C. Stratton for helpful discussions. This work was supported by U.S. Department of Energy Contract No. DE-ACO2-76-CHO-3073. 


\section{References}

[1] I, Schivell, Rev. Sci. Instrum. 56, 972 (1985).

[2] B. Lipschultz, B. Labombard, E. S. Marmar, M. M. Pickrell, J. L. Terry, R. Watterson, S. M. Wolfe, Nucl. Fusion 24, 977 (1984).

[3] F. P. Boody, C. E. Bush, S. S. Medley, H. K. Park, and J. Schivell, Proc. of the 7 th Internat. Conf. on Pldsma-Surface Interactions in Controlled Fusion Devizes (May, 1986) J. Nucl. Mater. (in press).

[4] P. Smeulders, Nucl. Fusion 26,267 (1986).

[5] J. E. Camacho and R. S. Granetz, Rev. Sci. Instrum. 57, 417 (1986).

[6] G. A. Cottrell, E. S. Fairbanks, and R. E. Stookdale, Rev. Sci. Instrum. 56, $984\langle 1985\rangle$.

[7] S. S. Medley,' D. L. Dinock, S. Hayes, D. Long, J. L. Lowrance, V. Mastrocola, G. Renda, M. Ulrickson, and K. M. Young, Rev. Scl. Instrum. 56, 1873 (1985), and S. S. Medley, private communication.

[B] H. Park, D. K. Mansfjeld, L. C. Johnson, and C. H. Ma, Rev. Sei. Instrum. $\underline{56}, 938$ (1985), and H. Park, private communication.

[9] G. T. Herman, A. Lent, and P. H. Lutz, Commun. Ass. Comput. Mach. 21, $152(1978)$.

[10] J. Schive11, IEEE Trans. on Plasma Sci, PS-8, 226 (1980).

[11] B. C. Stratton, private communication.

[12] K. Bockasten, 4. Opt. Soc. Am. 51, 943 (1961). 


\section{Figure captions}

[1] Lines of sigit of bolometer arrays. The arrays are $162^{\circ}$ apart toroidally. The solid and dashed circles represent the two largest plasmas allowed by the limiters.

[2] Chord-integral intensity measured by the tiwo bolometer arrays at $2.5 \mathrm{~s}$ in a discharge with a "marfe" [see text]. The part of the vertical-view profile outside of shannel 10 is considered normal. The dashed lines are the results of integrating the reconstructed emittance.

[3] Chord-integral intensity (horizontal view) as a function of channel and time for the same discharge as Fig. 2. The bright feature drifts from bottom top. During the same time there is a peak in the vertical view which drifts from channel 7 to channel 2 .

[4] Division of plasma cross section into zones for enittance renonstruction. Dotted circle is the vacuum vessel.

[5] Plots of emittanoe as a function of position for nine times, showing drift of the marfe and its evolution into a detached plasma limited by a radiating shel1. The height of the surface is proportional to emittance. The view is looking inward toward the torus major axis; the top of the plasma is on the right. The chord integrals at $2.5 \mathrm{~s}$ are shown in Eig. 2.

[6] Chord-integral intensity, horizontal view (a) and vertical visw (b), and reconstructed emittance distribution (c) for a discharge with a central radiation peak as well as a marfe. 


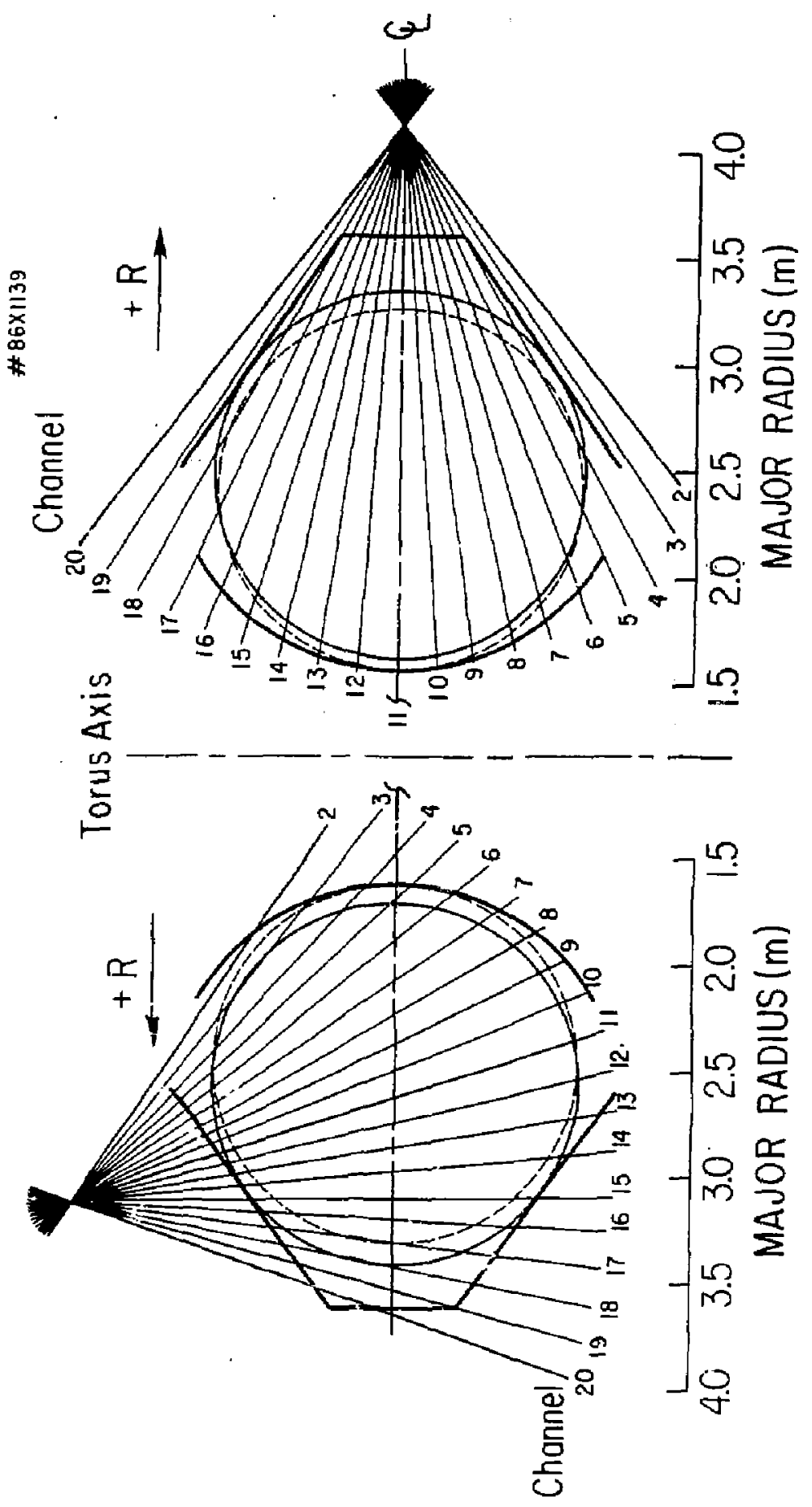



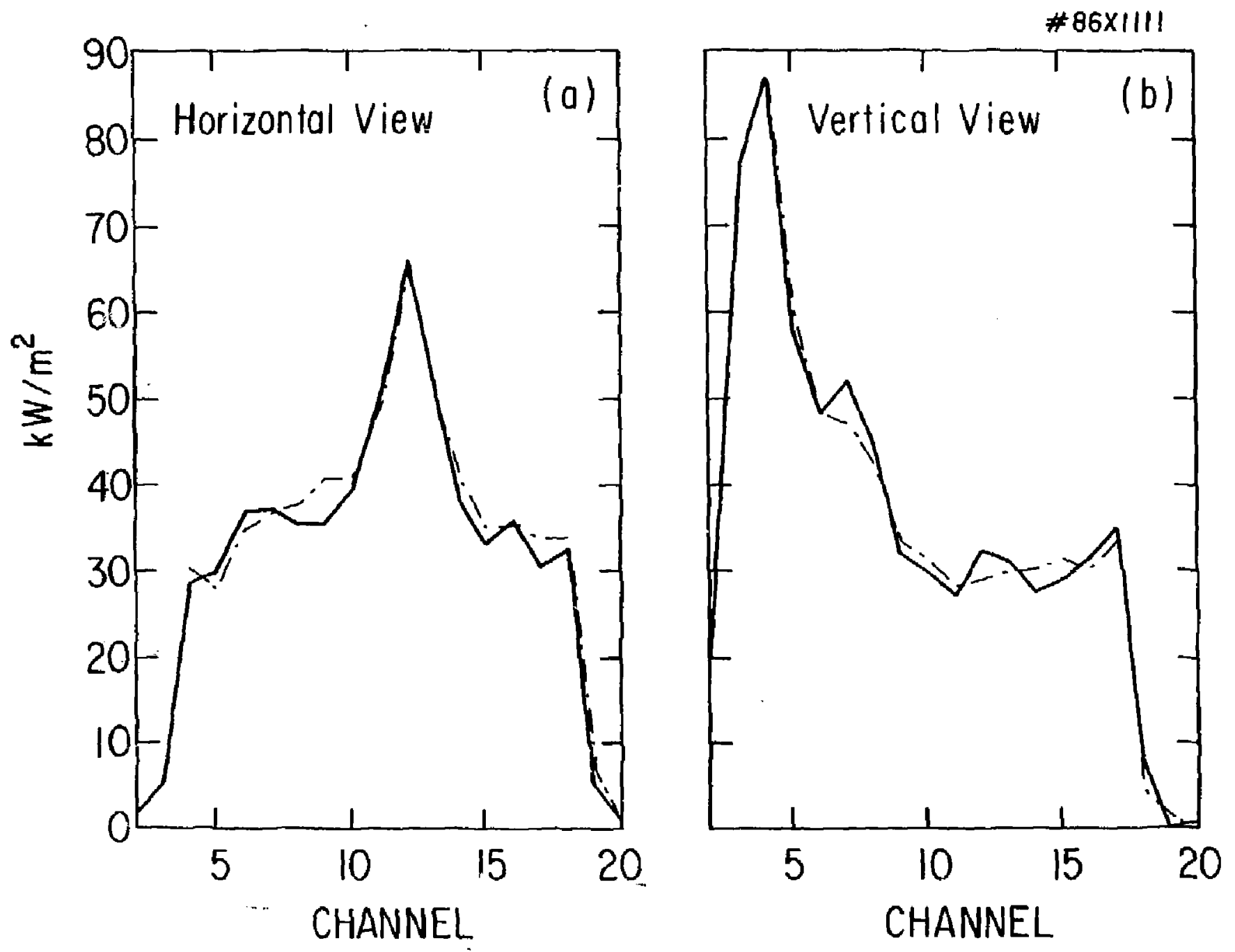

Fig. 2 


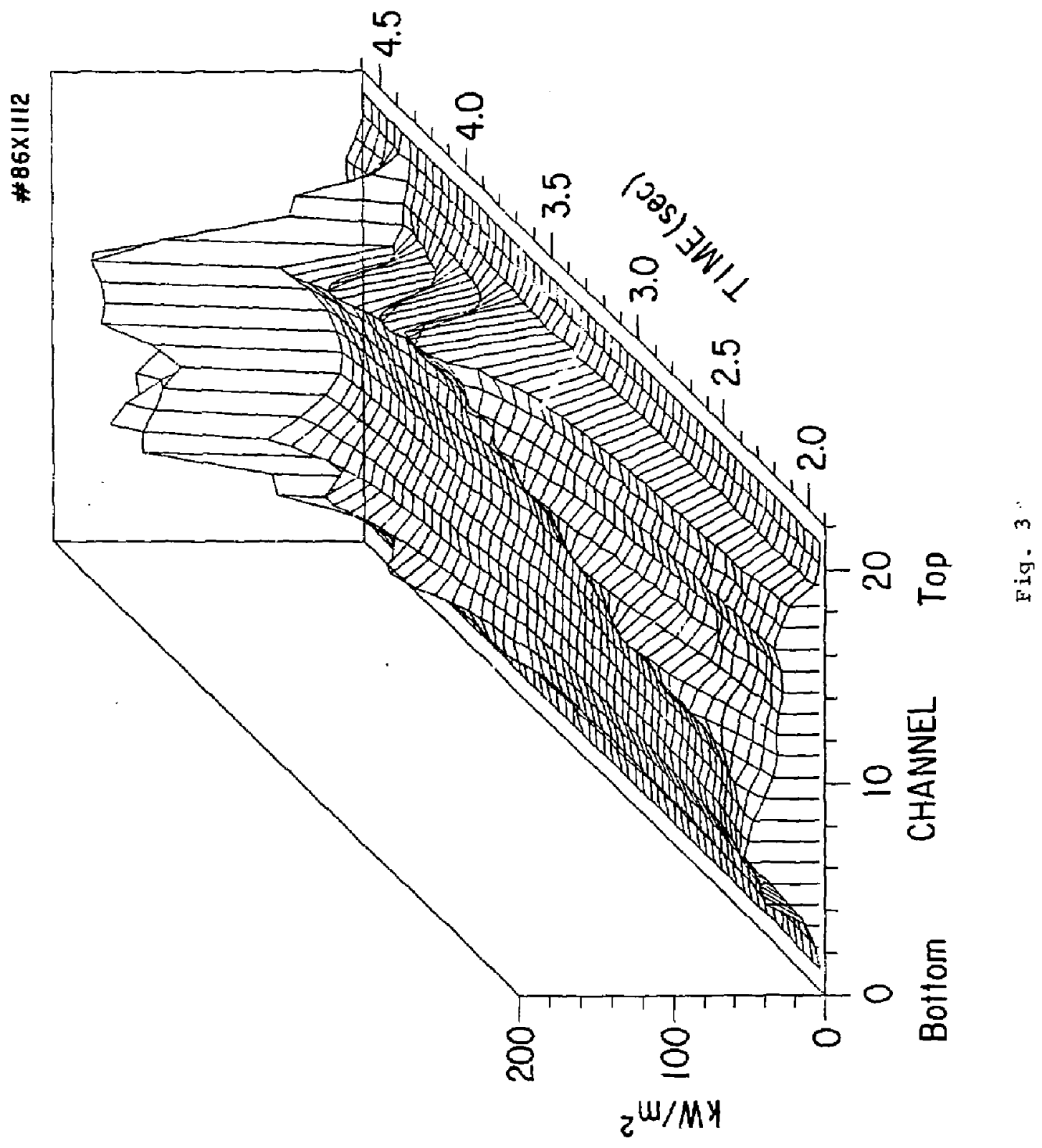




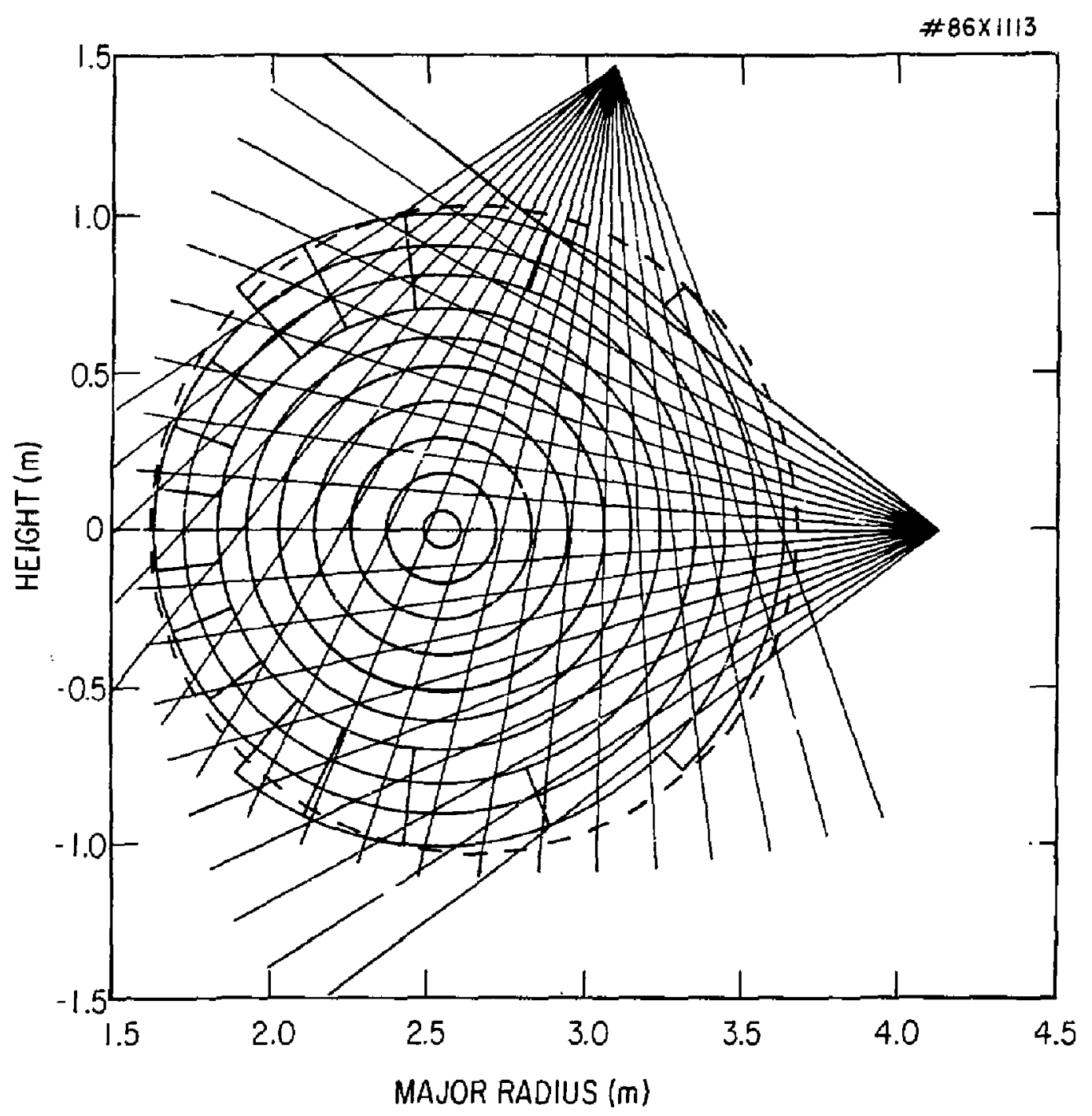

Fig. 4 
产
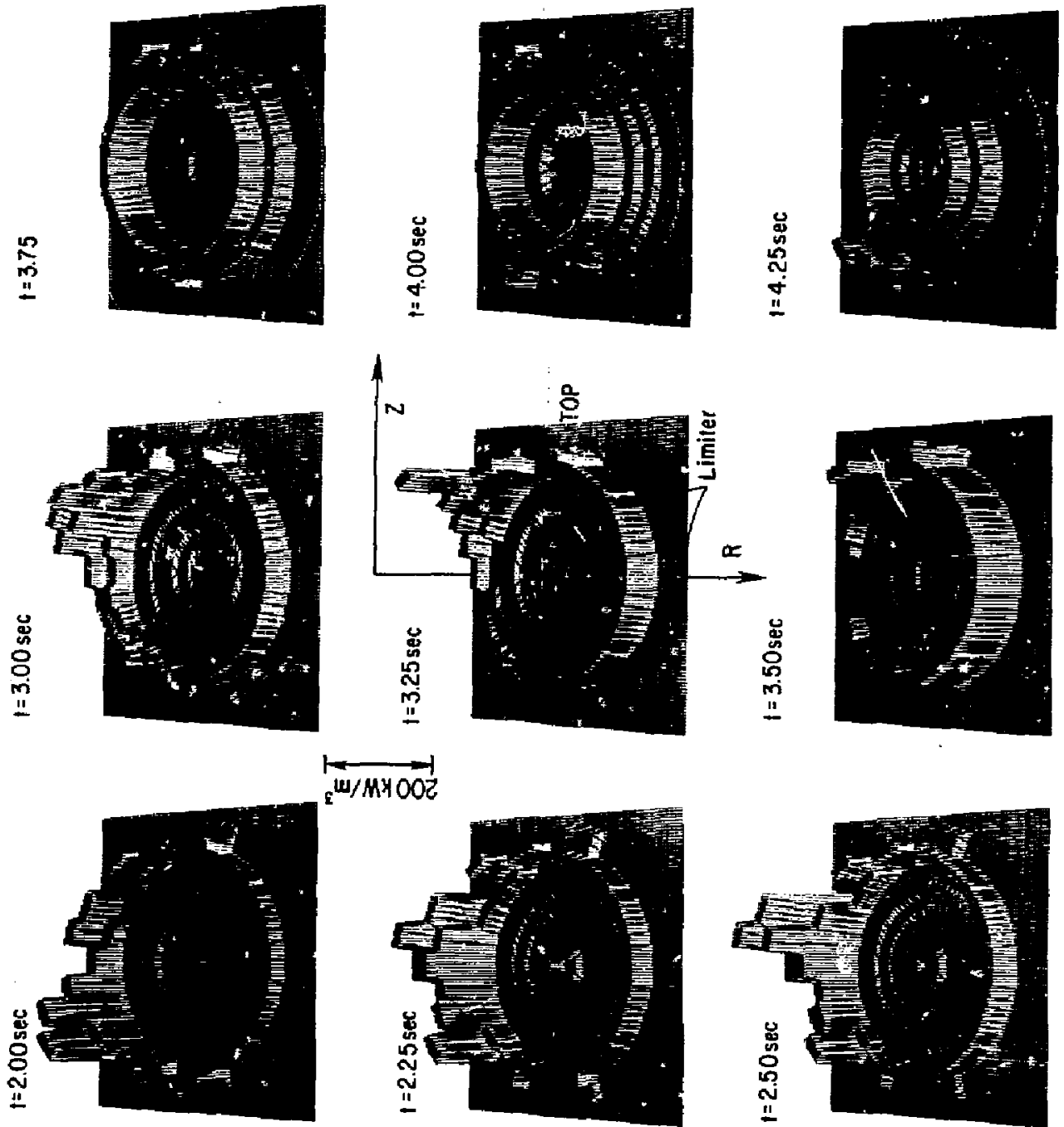

$\overrightarrow{w / M H O O Z}$
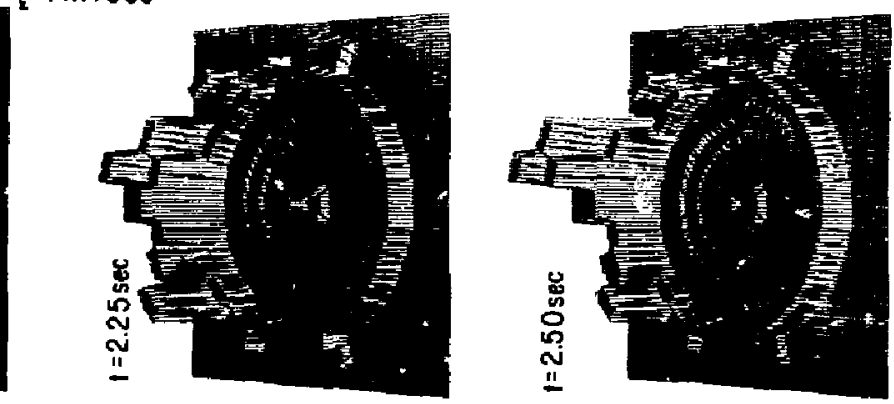

15

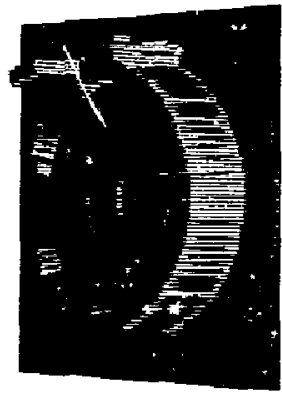



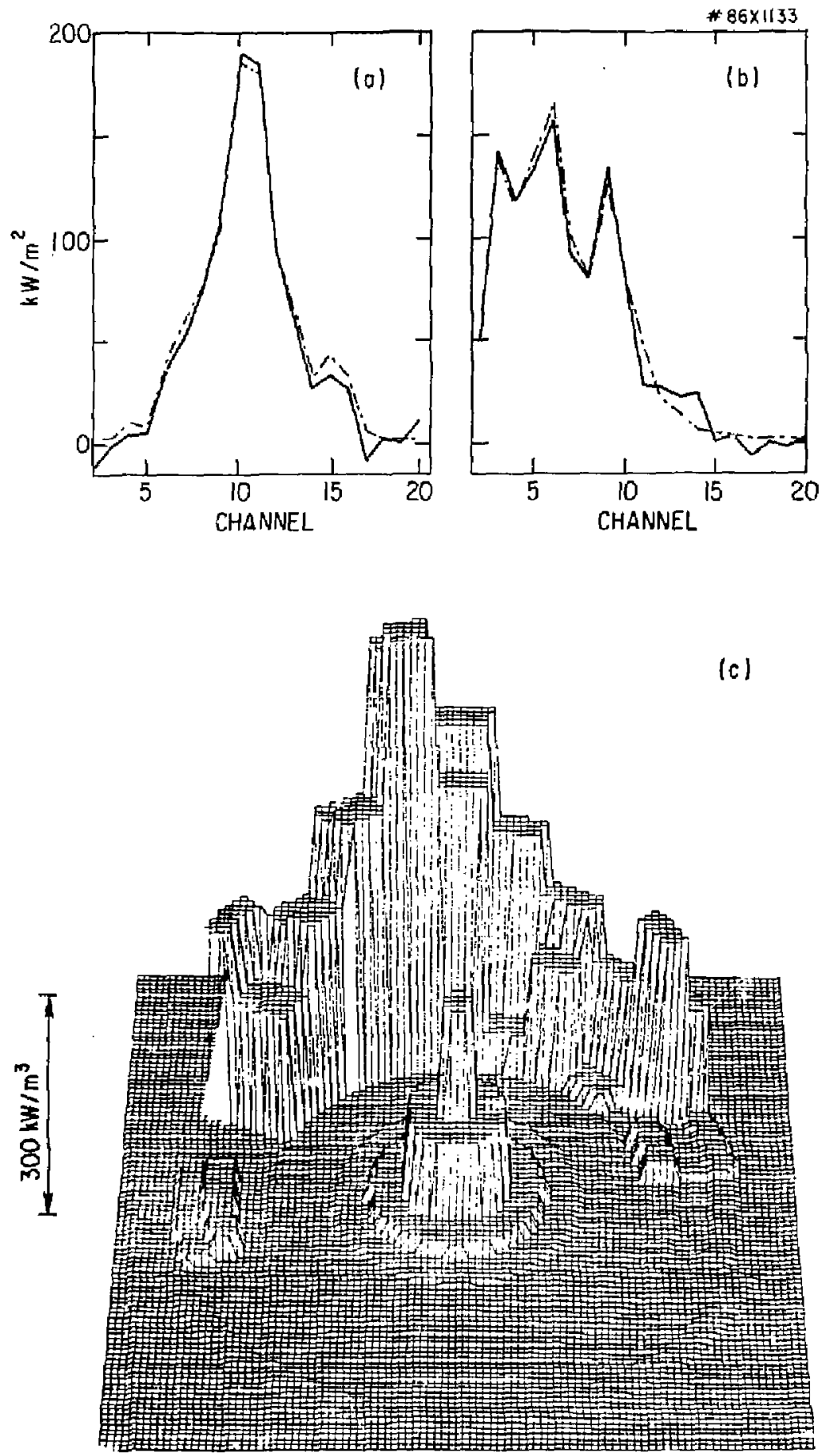

Fig. 6 
Plasmo Res Lab, Austra Nat'I UnIy, AUSTRAL IA

Dr. Frank J. Paolonl, Unlu of wollongong, AUSTRALIA

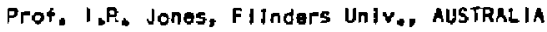

Prof. M,H, Brennan, Univ Sydner, AUSTRALIA

Prot. F. Cap, Inst Theo Phys, AuSTRIA

M. Goossens, Astronomiseh Instituut, BLLGIUM

Prot. R. Bouclque, Laboratorlum voor Natuurkunds, BELGium

or. D. Palumbs, Og Xil Fuston Prog, aELGIuM

Ecole Rayale MIIItalro, Lab de Phys Plasmas, BELGIUM

Dr. P.H. Sakanaka, Univ Estadual, BRRIL

LIb. \& Dac. Div.. Instituto de Pesqulsas Espaclala, GRAZIL

Dr. C.R. James, UnIr of Alberta, CAMAOA

Prot. J. Telchmann, Unlv of Montreal, Canada

Dr. H.M. Skarsgard, Univ of Saskatchewan, CANADA

Prof. S.R. Sreanlyasan, UnlversIty of Calgary, CANADA

Prof. Tudor $H$, Jahnston, IMRS-Energlo, CANADA

Or. Hannes Barnard, Univ aritish Columbla, CANADA

Dr. M.P. Bachynski, PB Technologles, Inc., CANADA

Chalk RIver, Nucl Lab, CANADA

Znengw Li, SW Inst Physles, CHINA

Library, Tsing Hua University, CHINA

LIorarlan, Institute of Finsles, CHINA

Inst Plasma Phys, Academla Sinlca, CHINA

Dr, Petar Luxac, Komenskeho Unly, CECHOSLOVAKIA

The Librartan, Culhen Laboratory, ENGLAND

Prot. Schatzman, Observatolro do Nlco, FRANCE

J. Radat, CENGAPG, FRAHCE

JET Reading Room, JET Jolnt UndertakIng, EMGLAMD

NA Dupas Library, Nh Dupas Library, FRAMCE

Dr. Ton Mual, Acadomy gibllographle, HOHG KOHG

Preprlat Library, Cent Res Inst Phys, HUAGARY

Or. R.K. Chnojlani, VIkran UnIr. IMDIA

Dr. B. Dasgupta, Saha Inst, INDIA

Or. P. Kar, Physleal Research Lab, INDiA

Dr. Phillip Roseneu, I srael Inst Tech, ISRAEL

Prat. S. Cuparman, Tol Aviv UnlvorsIty, IJRAEL

Praf, G. Rostagni, Univ OI Padova, ITALY

Librarlan, Intil Ctr Theo Phys, ITALY

Miss Clella Do Palo, Asso EURATOM-ENER, ITALY

BIbllotesa, del CNR ELRATOM, ITALY

Dr. H. Yamato, Toshlba Ros \& Dov, JAPAN

Direc. Dept. Lg. Tokamak Doy, JAERI, JAPAN

Prof. Nobuyukl Inowe, University of Tokyo, JAPAN

Regearch Info Canter. Nagoya Unlverslty, JAPAM

Prot. KYoJl N1shlkawo, Unly of HIroshimg, JAPAN

Prot. Sigoru Morl, JAERI, JAPAN

Prof. S. Tonaka, Kyoto University, JAPAN

LIbrary, Kyoto Unlvorsity, JAPAN

Prof. Ichlro Kavakaml, Nihon Univ, JAPAk

Prof. Satoshl Itoh, Kyushu UnIversity, JAPAN

Dr. D.l. Chol, Adv. Inst Sel \& Teeh, KOREA

Toch Info Olvision, KMERI, KOREA
Bibllothook, Fon-l nst Yoar Plaseno, NETHERLFNDS

Prof. B.S. Lilley, Unlversity of Wolkato, NEW ZEALAND

Prof. J.A.C. Cajral, Inst Superior Tecn, PORTJGAL

Dr. Oetarlan Petrus, ALI CLCA UnIvarslty, ROMANIA

Prot. M.A. Halloerg, Universlty of Natal, SO AFRICA

Dr. Johan de Villiers, Plasmi Phystes, Nucor, SO AFRICA

Fuston DIv. LIbrary, JEN, SPAIN

Prof. Hans wilheinson, Chalners UnIv Toen, SWEDEN

Dr. Lennart StenfIO, University of UMEA, SWEDEN

LIbrary, Royal inst Tech, SWEDEN

Centre de Racherchesen, Ecole Polytech Fod, SWITZERLAND

Dr. V.T. Tolok, Kharkoy Phys Tach Ins, USSR

Dr. D.D. Ryutov, Sl berlan Acad Sci, US5R

Dr. G.A. Ellseev, Kurchatou Institute, USSR

Dr. V.A. Glukhikh, Inst Electro-Physlaal, USSR

Institute Gen. Physles, USSR

Prot. T.J.M. Boyd, UnIv College N Woles, WALES

Dr. K. Schindler, Ruhr Univarsitat, w. GERMANY

ASDEX Reading Rn, IPPAhaxPlanck-InstItut fur

PIjsmephysik, F.R,G.

Nuclear Res Estab, Julleh Ltd, W. GERMANY

Librarlan, Maxtlanck Instltut, W. GERMANY

alollothek, Inst Plasmatorschung, W. GERMANY

Prot. R.K. Janev, Inst Phys, YUgosLaviA 